\title{
TRANSLATION AS DISSEMINATION: A NOTE FROM AN ACADEMIC AND TRANSLATOR FROM BENGAL
}

\author{
SWATI GANGULY
}

Abstract: Translation Studies and Postcolonial Studies have emerged as the two most significant areas of cultural studies in recent times. The purpose of this essay is to explore the link between the two, through the practice of translating postcolonial fiction from Bangladesh with special focus on the short stories of Humayun Ahmed, a major contemporary writer of Bangladesh. Most postcolonial theory continues to uphold the dominance/hegemony of English since it is the language in which such studies are conducted both in the West and the erstwhile colonies. However, despite the phenomenon of the Empire writing back a large number of writers from postcolonial nations write not in English but in their own national language. Hence, postcolonial theory in its negotiations with postcolonial literatures is dependent on the availability of English translations of nonEnglish/vernacular fiction. The choice of fiction from Bangladesh was based on the fact that its identity as a postcolonial nation is integrally linked to a language 
named Bangla or Bengali. Unlike India, Pakistan or Srilanka, which have witnessed the rise of literature in English, Bangladesh has zealously maintained its unique linguistic identity and the narration of this nation has been almost exclusively in Bangla. Hence, it is little wonder that the postcolonial literature from Bangladesh has remained largely ignored by postcolonial critics and is seldom included in the curriculum of Postcolonial Studies. The aim of translating Humayun Ahmed's stories is a small step towards putting the fiction from Bangladesh on the map of postcolonial literatures. For discourses of translation the value of a translated work was often and still is, determined by the extent to which it can read as if it were written in the target language itself. Expectations of fluency imply an effacement of the very process of translation that makes a translated text available. Such invisibility of the translator and the translated work has ideological implications that are often ignored. Translation is not merely an aesthetic and literary activity that involves two languages but is a process embedded in cultural systems. That a translation be read like an original, implies an erasure of the cultural specificities of the cource language and establishes the cultural hegemony of the target language. Postcolonial translation is a radical practice that is aware of the politics of translation and is committed to maintaining the nuances of cultural difference and not domesticating the source language/vernacular text.

The term 'post-colonial translation' has gained currency in contemporary seminars and workshops but there seems to be little consensus among speakers/academics about its meaning and implications. In seminars there are still lengthy discussions of the pressing need to provide English equivalents of culture- 
specific ancient Indian/Aryan class terms like kshatriya as 'baron' (to provide a mild example) in order to make the Indian epic more intelligible and acceptable to an Anglo-American readership. Clearly the term 'post-colonial' appended to translation carries little or no significance and it functions as a fashionable and eye-catching garnish to a commonplace dish necessary to ensure its place in the academic carnival banquet. It is with a remembrance of such amazing encounters that I venture to clarify at the outset what I understand by the term 'post-colonial translation'.

I shall attempt to explore the significance of the term 'post-colonial translation' by tracing the links between Postcolonial Studies and Translation Studies especially as they obtain in the academia. I shall begin by examining briefly the current ideological position of post-colonial studies, which upholds the hegemony of the English language and the political/ideological implications that it has for post-colonial regional/vernacular or what has gained currency as bhasha literatures. Post-colonial translation, as I understand it, refers both to translations of non-English post-colonial literatures as a sustained and systematic effort of dissemination of these texts as well as to a methodology that draws on current translation theories to evolve a radical practice that can be termed 'post-colonial'.

The second section of my paper is more personal and is concerned with my role as an humble teacher concerned with the future of English Studies and as a practising translator who just has two languages, viz. Bangla and English at her command. My choice of translating creative fiction from Bangladesh was at one level a conscious attempt to effect a 
change in my own/our understanding of post-colonial studies as we choose to define it in the rrarrow confines of the curriculum. It was occasioned by the sheer excitement of reading Humayun Ahmed, a popular fiction writer from Bangladesh whose nuanced satire of the post-colonial condition created an impulsive desire to translate the stories from Bangla into English.

Post-colonial Studies may be regarded as a new entrant in the academic curriculum of Indian Universities staking its claim in the syllabi of English departments only in the 90's. The two factors responsible for its emergence were the development of a powerful body of post-colonial theories and the 80's phenomena of the Empire writing back in the language of its erstwhile masters/colonizers.

These 'new makers of World fiction', as Pico Iyer terms them, are a generation of writers from post-colonial nations, who truly reap the benefits of a globalized economy. Recipients of prestigious literary awards and whooping sums of advance, these writers enjoy a power and prominence in the world literary market unimagined by those who wrote fiction in English in the 30's or 60's. Tracing the contours of this difference is outside the purview of this paper, and I mention the global image of the English language writer from postcolonial nations because it has had serious consequences for the notion of post-colonial literary productions per se. The oftquoted statement by Salman Rushdie is a case in point. ${ }^{l}$ Recently a similar statement made by V.S. Naipul sparked off the Nimrana debate. Indeed so strong and influential has been this rather ridiculous swagger of vanity and ignorance expressed by post-colonial English writer-critics, that we now 
have to resort to underlining the obvious; i.e. the post-colonial nations like India also produce significant and powerful Indian regional language litrartures, or bhasha literatures, as we have come to call them, meaning, 'indigenous regional language literatures of india'. In spite of its hundreds of years of sophisticated and evolved literary tradition, bhasha literatures are now orphans in a global market that refuse to grant them legitimacy and recognition. The Empire it seems is writing back with a vengeance and in the process settling a score with its own sibling, the vernacular or bhasha literatures that had once regarded it as an imposter and foundling in the heyday of the Empire.

At this point I wish to digress a little to talk about the role of the English language as shaping the literary/intellectual minds in Bengal from the mid $19^{\text {th }}$ to mid $20^{\text {th }}$ century and the two-way traffic that existed between English and vernacular literatures.

Perhaps the best example of the reversal of fortunes of English language writers of the Empire can be traced through the careers of two English educated elite Bengali young men in the early $/$ mid $19^{\text {th }}$ century. Michael Madhusudan Dutt and Bankim Chandra Chattopadhyaya both began their creative writing careers in English that were regarded as 'false starts'. Dutt went on to record thus in his famous sonnet (included now in almost all Bengali school textbook anthologies) in which he lamented his own ignorance and folly in his inability to recognize the rich jewels of Bangla and covet the goods of the English language like a beggar. 
Bankim Chandra whose first novel Rajmohan's Wife sank without a trace advised young men like Romesh Chandra: "You will never live by your writing in English...Govind Chandra and Sashi Chandra's English poems will never live, Madusudan's Bengali poetry will live as long as the Bengali language will live." But this celebration of the mother tongue as the vehicle of creative writing was by no means an insular or chauvinistic/parochial tendency. Even if we leave aside the genius of Tagore who embraced internationalism as the credo in his writing, philosophy and pedagogical innovations the bourgeois Bengali in the post-independence era had afways operated in two worlds, the world of English/Europe and Bangla.

Indeed in the 1840 's/50's Bengali intellectuals and writer-critics like Buddadev Bose, Bishnu Dey, Sudhindranath Dutta, Samar Sen were not only formidable scholars of English and European literature, but were prolific translators of English and European works and especially modernist/symbolist poetry into Bangla. This traffic from the west through translation, not only of texts but of critical thinking, played a significant role in setting the trends of post-Tagore Bangla literature. However not only is such creative/critical bilingualism largely on the wane, but also there is an attendant malaise amongst the middle-class educated younger generation of Bengalis who affect a disdain for Bangla literature and language. It is ironic that the parents of Bengali youngsters would encourage them to read the Bangla nonsense verses of Sukumar Ray in translation. This I'm afraid indicated not a recognition of the genius of the translator Sukanta Chudhury, but a social snobbishness, a mind-set that associates only English with 'great literature'. 
In the agenda of Post-colonial Studies Bhasha literatures thus have to contend with the sheer power and prominence of post-colonial English literatures on the one hand and the dominance/hegemony of English language as the medium through which such studies are conducted on the other. The blinkered vision of post-colonial literatures can only be corrected, it seems, through dissemination of the postcolonial bhasha literatures in English translation. Indeed one might say that it is the post-colonial predicament of the nonEnglish writer that her/his identity as a post-colonial writer hinges on the critic/readers' accessibility to her/his works in English.

A famous case in point is that of Mahasweta Devi who was translated into English in the early eighties by the prominent Marxist feminist deconstructionist academic Gayatri Chakrabatri Spivak. By the seventies Mahasweta Devi was well known as a powerful writer in a section of Bengali readers and also widely known through the translation of her works into other Indian languages. However, her entry into the postcolonial agenda and her canonical status in the curriculum of Post-colonial Studies (she is now a part of the post-colonial canon) was largely the effect of the prestige of her English language translator in the western academia.

Since English is the linguistic register of postcolonialism, English language translation thus determines the visibility of the writer from multilingual ex-colonies to the West and at home. It is at this crucial juncture that postcolonial translation as a radical practice comes into being and 
must be distinguished from the indigenous traditions that have existed in India over a long period.

As Meenakshi Mukherjee observes, "Translations have always been a vital part of Indian literary culture even when the word 'translation' or any of its Indian language equivalents - anuvad, tarjuma, bhasantar or vivartanam - was not evoked to describe the activity" The important point to note is that such anuvad, tarjuma or bhasantar almost never drew attention to its own status creating a notion of seamless narratives that are a part of an entire body of writing from a culture. However, what was evidently a virtue/plus point in the indigenous tradition can take on an entirely different political/ideological connotation when translations occur in the powered relations that exist between languages such as vernacular and English in a colonial and post-colonial context. I shall return to this shortly in my discussion in which current translation theory has paved the way for a radical revision of translation practice.

Mukherjee also points out that there was a healthy tradition of translation from one vernacular into another by which a reader of Kannada or Marathi could access literature in Bangla or Oriya without the mediation of English. This form of continuous cultural exchange and interaction accounted for making India into a nation that is 'a translation area'. However, this has lamentably declined over the years for the sheer lack of translators who are proficient in another Indian bhasha or vernacular apart from her/his mother tongue. It is at this point that one has to look into the role played by the state supported Sahitya Akademis that were set up with the purpose of translating the representative or best works of 
regional/vernacular/bhasha literatures into English. Inspite of its attempts to foster across cultural exchange with the objective of linking literatures, as Ritu Menon points out, in these noncommercial ventures the quality of translation and production values were secondary. Menon's essay also traces the development in the 60's of private publishing houses, like Jaico, Hind Pocket Books, Sangam Books, Vikas, OUP and Bell Books that took up translation as viable commercial ventures. Even as these houses ceased publication or became sporadic in their attempts in the late 1980's translation received an extra fillip through 3 independent publishing companies namely Kali For Women (1984), Penguin India (1985) and Katha (1988). I am not equipped to go into a discussion of the roles of these and other publishing enterprises as the disseminator of translations. Suffice it to say that as a feminist academic/teacher I find it invigorating that Kali with its avowed aim of dealing exclusively with women's writing created a kind of revolution in feminist/women's studies in India. It paved the way for feminist scholars who have used translation as a tool of recovery and discovery of forgotten and neglected women writers from bhasha literatures. This in turn has opened up new directions for research into women's contribution in history, politics and literature in various disciplines in the universities and centers for culture studies. However, inspite of the spate of translation activities that now mark the publishing enterprise there is little consensus among them about the theoretical underpinnings of such work. Thus it is difficult to trace the emergence of a theory and methodology of translation of these texts, which is indispensable for translation studies and post-colonial studies in the academia. The presence or the lack of translation apparatus such as glossary, a detailed translator's note/preface along with an 
indication of the status of the original or publishing houses. However, such inconsistencies and neglect go a long way in perpetuating the short shift that is given to translation in our culture. An awareness of the politics of translation cannot be treated as the special provenance of post-colonial culture critics who have shown how Orientalist translations in colonial Indian served as a tool of hegemonic control. This is where academic institutions/universities can step in to work in tandem with publishing houses taking up translation projects which, using contemporary translation theory, can turn the practice into a radical cultural-political one.

Traditionally the two F's have dominated translation practice. These are Fidelity and Faithfulness to the source language text and its fluency in the target language. Male practitioners and theorists of translation have often expressed their frustration with these twin demands made of translation as a near impossible task equivalent to finding a woman who is faithful and yet beautiful. In this age of gender-sensitivity and the need to be politically correct, such sexist comments perhaps are less likely to be put stridently in print. However, their unstated presence however looms large in translation reviews in the popular print media. I shall choose to discuss the cultural and ideological implications of 'fluency' because publishing houses continue to prioritize this as a marker of a good translation above everything else. For the average reader this seems like a reasonable demand that a good translation is one that reads as if it were produced in the target language itself. However, it's pernicious effect works both on the status of the translator as well as the translated text, whose ideological/cultural-political implications have been discussed extensively by Lawrence Venuti. 
A fluent strategy aims to efface the translator's crucial intervention in the foreign language text: he or she actively rewrites it in a different language to circulate it in a different culture, but this very process results in a self-annihilation, ultimately contributing to the cultural marginality and economic exploitation which translators suffer today. At the same time, a fluent strategy effaces the linguistic and cultural difference of the foreign text: this gets rewritten in the transparent discourse dominating the target language culture.... In this rewriting, a fluent strategy performs the labour of acculturation which domesticated the foreign text making it intelligible even familiar to the target-language reader, providing him or her with the narcissistic experience that extends the dominion of transparency with other ideological discourses over a different culture.

Venuti's analysis of the politics of 'fluency' and 'transparency' that end up in 'domesticating' a text and perpetuating cultural hegemony, the 'imperialism' of the target language is a theoretical position that can be profitably used to understand the role of translation in the post-colonial context. It is crucial to continually remind ourselves that with the lure of a global market for translated post-colonial texts the temptations of fluency and transparency can be immense. But to do so would be to participate in a cultural-linguistic imperialism that perpetuates the dominance of AngloAmerican cultures. As academicians practicing translation we need to rethink our roles in politics and build up a resistance to English language-culture hegemony. Thus practicing 
translators need to be aware of the links that exist between the ideological premises of Translation Studies and Post-colonial Studies.

Recent theorists of post-colonialism and translation have pointed out that 'colonialism and translation went hand in hand'. Apart from the translation projects undertaken by Orientalists who often removed all signs of cultural difference, scholars have traced the analogy between a work of translation and a colony. Both are copies of a source or original that implies an immediate devaluation of status and a position of subordination to the original. With post-structuralism and deconstruction radically revising the notion of original and questioning the status of authority/authorship recent translation theory has destabilized the relationship of power between the original and the translated text. In this context it is important to consider the radical potentials of the term uttarupaniveshbad (Hindi/Bengali for 'post-colonialism'). As Harish Trivedi has pointed out, the term contains within it the notion of an active dialogue (the Sanskit prefix uttar means both 'after' as well an 'answer and opposition to') with colonialism and its legacies.

Translating post-colonialists aim at providing such an answer and opposition to colonialism through a translation practice that is committed to maintaining the nuances and markers of cultural/linguistic difference of the translated works. This is in Venuti's words, 'foreignize', meaning a text bringing home the point so crucial to post-colonial studies that we are encountering a cultural 'other' and not attempt to efface it or render it invisible. As practicing translators we have to be conscious of the dangers of domesticating the vernacular text and resist a form of fluency that would convey the impression 
that it was written in English. The greatest stumbling block on the path of such radical practice is to run the risk of the critical common place of one's work being termed 'a bad translation' which invariably translates as 'it does not read like an English text'. I am of course not attempting to make a plea for or to uphold works of translation that are carelessly executed and are grammatically and syntactically sloppy or uneven. The crucial point is that we need to revise and monitor the kinds of expectation that we bring to a post-colonial translated text, which through years of our experience as the colonized we have internalized as 'natural' and legitimate. Perhaps a more fruitful way would be to recognize that a translated work can neither occupy the position of an original in the target language nor can it wholly be an unchanged version of the original. Rather it is a hybrid product that occupies a third space, a place of in-betweenness.

I now venture into the second section of my paper. About two years ago I found myself as a member of a committee set up to draft a new syllabus for our undergraduate and postgraduate English courses. For most of us in the department this meant a registering in the syllabus of the tug of the discipline of English towards culture studies. We wanted this change to be made at the postgraduate level by an inclusion of a compulsory paper called "Post-colonial Studies". This was to be divided into two sections. The first would attempt to familiarize the student with post-colonial theories and the second section would be a selection of post-colonial texts, primarily fiction. We wanted to resist the tendency to identify post-colonial fiction solely as the preserve of English language texts and wanted to include translated texts as examples of post-colonial writing. It was only then that we 
realized the non-availability in English translation of some of the Bengali texts that many of us would have liked to include. To give an example, Bibhutibhusan Bandopadhya's novels Aranyak and Chander Pahar (these titles would translate as $O f$ the Forest and The Mountain of Moon respectively) we felt were interesting examples of post-colonial texts that had never been translated. There has been since then an excellent translation of the first novel as Aranyak, done by Rimli Bhattacharya and published by Seagull Books, Kolkata. Incidently on the occasion of the launch of the book, Seagull arranged a symposium inviting some of the prominent academics, critics and litteratteurs of Kolkata to draw up their own list of what they regarded as the ten best novels in Bengali. The rationale of such a discussion was that it would provide the publishers a shortlist of Bengali fiction, which could be taken up as a translation project. Interestingly almost none of the novels mentioned was part of the mainstream popular fiction and many of them were long out of print. The reason why I mention this is that if we are to extend our knowledge of the range and variety of post-colonial fiction, then these novels will have to be discovered anew and translation ventures with specific ideological and cultural aim of dissemination will have to be undertaken if they are ever to find a Benjaminian 'after life'.

It was grappling with the task of drawing up a list of Bengali texts available in English translation that the complete omission of writing from Bangladesh in any discussion of post-colonial studies occurred to me as a distressing gap. One reason for this was perhaps unlike India that has witnessed the rise of fiction in English the narration of this nation has happened almost entirely in Bengali. Indeed it is possible to 
say that translation, as dissemination, is particularly pertinent in the case of Bangladesh. This is because its identity as a postcolonial nation is integrally linked to Bengali, which is also the language of West Bengal, the Indian state with which Bangladesh shares a border. Bangladesh came into existence initially as East Pakistan when the British, on the eve of their departure from India, decided to partition India on the basis of religion. Like sections of Punjab in the west, a portion of Bengal in the east with a Muslim majority population was made a part of Pakistan and named East Pakistan. The Bengali Muslims of East Pakistan, however, felt they had very little in common culturally and socially with West Pakistan and the first protest came against Urdu being imposed as the official language. The bhasha andolan, as it is popularly called, was a rebellion against linguistic domination. A bloody and violent struggle ensued which led to the death of several thousands and $21^{\text {st }}$ February came to be recognized as the day to identify. themselves with, a kind of National day for the people of East Pakistan. The landslide victory of the Awami League, a party based in East Pakistan, led to attempts by West Pakistan, primarily under the leadership of General Bhutto, to wrench political power from the hands of the leaders in East Pakistan.

The rebirth of East Pakistan as Bangladesh came in 1971 with Mukti Juddha or the 'freedom struggle' where Bengalis of East Pakistan fought against the military (popularly referred to as the Khan Sena) from West Pakistan. This twice-born nation has ever since zealously maintained its unique linguistic identity. Unlike India, Pakistan and Sri Lanka that have witnessed the rise of literature in English, the narration of this nation has happened almost entirely in Bangla. Given the monolingual nature of the state where all 
people have access to Bangla, it is little wonder that there is no felt need within the country to translate their literatures into English. Thus this amazing treasure trove of post-colonial literature produced in Bangladesh has remained largely ignored by critics and is seldom included in the curriculum of Post-colonial Studies either in India or in the West.

My first acquaintance with fiction from Bangladesh was through a translation project whose aim was to bring out an anthology of contemporary Bengali women's writing. I was intrigued by the distinctiveness of the writing by women of Bangladesh in terms of theme or content as well as the use of language. My curiosity in fiction from Bangladesh was further whetted by a piece of gossip concerning Humayun Ahmed ${ }^{3}$, one of the most popular contemporary Bangladeshi writers. Ahmed, we were told, had bought a small island and the source of his wealth was not inheritance but royalty from his books. This sounded like utopia. I began reading Humayun Ahmed rather skeptically with the preconceived notion that the popularity of a writer was directly proportional to the lack of serious cultural and ideological commitment in his work and was thrilled to be contradicted by what I encountered. It taught me a lot about the reading public and the literary culture of Bangladesh.

This brings me to the last section of my essay. In this section I shall use extracts from my translation of one of Humayun Ahmed's short stories, 'Fazlul Karim Saheb's Relief Work' to drive home the twin points of the need to translate powerful vernacular post-colonial fiction into English to provide a corrective to the myopic vision of post-colonial fiction in the contemporary Anglophone world, and to 
demonstrate the possibility of evolving strategies to counter pressures of transparency and fluency that obscure 'otherness' and perpetuate a form of cultural and linguistic imperialism.

Ahmed's forte is terse, cryptic and black humour and in this short story he uses irony to explore the predicament of a post-colonial nation reeling under the weight of poverty, international aid and bureaucratic red-tapism. The author's strategy in telling the story is to use the point of view of Fazlul Karim, a self important and inefficient minister who is deeply suspicious of his bureaucratic officials and team of relief workers, and feels that he is thwarted in his heroic attempt to go in search of flood victims to whom he has to administer foreign aid. A narrative voice of mock sympathy is used to underscore the fact that Karim is a pusillanimous being and quite incapable of getting a grip on the situation.

The minister is waiting in the steamer but the journey is delayed indefinitely:

"So what are we waiting for?" he asked in a disgusted tone.

"The sareng hasn't arrived, Sir."

"Why hasn't he come?"

"I do not know, Sir. He was supposed to come at nine o'clock"

Fazlul Karim Saheb looked at his watch. It was twenty minutes past eleven. He himself was supposed to come at eleven and was bang on time. The personal assistant, however, had only arrived at ten past eleven. They could afford to do such things simply 
because he was a mere deputy minister. "There is a chair on the deck, Sir. Please sit down and rest. Someone has been sent to fetch the sareng".

He sat down on the cushioned cane chair loaking displeased. Quite a few chairs were empty but everyone else remained standing. In a magnanimous tone he said,

"Why are you standing? Please take a seat. One never knows when this steamer will leave. Bangladesh is a country where nothing happens on time".

"Only the flood Sir, is quite regular"?

Fazul Karim Saheb was thoroughly displeased. This was a comment from the fellow with the darkglasses. It was a good repartee. He did not possess this gift. Witty phrases came to his mind but usually long after a conversion had ended.

After they finally embark upon the journey, the minister expresses a wish to take stock of the material on board:

"Who has the list of the relief material that we are carrying with us"?

"I have it, Sir".

"Well, go on tell me what we have"? 
Hamid Saheb opened his file and brought out a list.

"Five hundred bottles of distilled water. Each two litres"

"What are we going to do with distilled water"?

"I wouldn't know, Sir. Seems like medical supply. We also have two bundles of boric cotton". stuff".

"We may get beaten up if we arrive with all this

"That is quite likely to happen, Sir. Quite a few relief teams have already been beaten up badly. Their clothes were stripped off and they were sent back naked".

"Are you trying to act smart with me? Is this some kind of a joke"?

"No Sir, this is the truth. One group. Probably some teacher's committee had gone with children's school texts, exercise books and pencils. They suffered this fate".

Fazlul Karim Saheb became very serious.

The fear of an imminent storm forces the party to retrace its course. They find a family afloat on a makeshift raft of banana stems and after a lot of 
coaxing and cajoling they condescend to steer the raft near the steamer. The minister orders that they be given the regulation supply of clothes and also a tent:

In a small voice Hamid Saheb enquired what they were to do with a tent.

\section{"Let them do whatever they please. Just follow my orders".}

"The raft will sink under the weight of the tent, Sir."

"It will not sink".

The family was not willing to take the tent. Instead they came on board. There was a young girl who vomited as soon as she stepped on to the steamer. Fazlul Karim Saheb was petrified. Did that indicate the girl had cholera, he wondered. It was awful. He went into a foul mood and spent the rest of the journey locked in his cabin. He had fever.

The following day leading newspapers carried accounts of the relief work done by Fazlul Karim Saheb. The reports stated that the deputy minister of the Human Resources Department Janab Fazlul. Karim Saheb had undertaken relief work under extreme adverse conditions and thus reinforced the pledge of the government in pulling out all stops to combat the flood situation. Following the superhuman effort that he put in for twenty-four hours in very foul weather Fazlul Karim Saheb had fallen ill 
and had to be admitted to the Medical College hospital. The minister for Human Resource, Janab Ekhlas Uddin visited him in the hospital and garlanded him. In a tremulous voice he said that in the present situation people like Fazlul Karim Saheb did not hesitate to lay down their lives for the suffering and the poor. He rounded up his speech by quoting two lines of a poem written by Rabindranath Tagore in a voice choked with emotion "Ke ba age pran koribek dan tari lagi karakari". ("There is a tussle now amongst people to be the first martyr".)

In this brief extract I have retained original Bengali words, Sareng, Saheb and Janab because they are culturespecific words whose nuances would be lost in their English equivalents. A sareng is a sailor in charge of a steamer and responsible for setting the course and steering it. Its closest equivalent would be 'captain' or the archaic 'boatswain' which I deliberately avoided because it carries a typical English connotation and would fail to convey the visual image of the working-class Bangladeshi Muslim that is immediately evoked by the mention of the river journeys in the country furrowed by countless streams and quite distinct from the association that a sailor or captain carries. Saheb (whose equivalent would be 'mister') is similarly retained because it is a form of address specific to the Muslim community and indicates a middle class gentleman, an esquire. In a Non-Muslim Bengali context the equivalent of saheb would be $b a b u$ and saheb which came into circulation in the $19^{\text {th }}$ century to signify a white English or European would be used in contemporary Bangla to refer to a bureaucratic official of a particular rank, primarily the head of an office. Janab is derived from Urdu and is used to refer to a 
gentleman who is highly respected. Once again it is term specific to Muslim culture and peculiar to the Bangla of Bangladesh.

Retaining words of the source language that have certain cultural specificities and providing a glossary is indispensable for 'foreignizing' a text and serve as a strategy that will resist the temptations of fluency and transparency. I have kept the original Bangla of Tagore's poem and am providing the translation in parenthesis primarily because these two lines are very famous and serve as a kind of metonym for the nationalist struggle for Independence.

The other problem that is encountered as a translator of a Bangla text is the stylistic peculiarities of the language that seems to facilitate a present tense or a present continuous tense in the narrative. This coupled with very short sentences that often appear to be fragments or incomplete sentences but works perfectly well in Bangla, creating a sense of unfamiliarity that most translators wish to eliminate since it becomes an immediate stumbling block for the English language reader because this is seldom the practice in English. I do not claim to have been able to deal with this problem entirely since charges of syntactical errors are far more difficult to handle than the issue of lexical peculiarities. However, I have tried not to smoothen out the rough edges altogether so that the reader of these short stories is able to experience that $\mathrm{s} / \mathrm{he}$ is encountering a translated work.

As a translator I realized that despite my access to the Bangla language I had to be continually conscious of the cultural differences and ideological imperatives that inform the 
usage of Bangla in Bangladesh. It was this constant process of re-learning and negotiation with Bangla that I shared, yet at the same time that I was distanced from, which created the unique sense of experiencing the unfamiliar within the familiar. I would like to express this as an experience of in-betweenness, which is indispensable to the post-colonial translator.

\section{Notes}

1. Rushdie claimed that the post-47 Indian writing in prose "both fiction and non-fiction is ... proving to be a stronger and more important body of work than most of what has been produced in the eighteen 'recognized' languages of India, the so-called 'vernacular languages at the same time". (Meenakshi Mukherjee: 2000)

2. I have in mind of course the encyclopedic work edited by Susie Tharu and K. Lalitha (see Tharu and Lalitha 1991), not to mention a large number of autobiographies and memories that have been translated by feminists in recent times.

3. A note on Humayan Ahmed: Born in 1948 in the Maimansingh district of Bangladesh, Ahmed studied Chemistry and received his Ph.D. from North Dakota State University, US for his work in polymers. Ahmed is a faculty member of the Department of Chemistry in Dhaka University. His first novel was published in 1972 and in that sense his birth as a narrator coincides with that of his nation. A prolific and powerful writer, Humayun Ahmed has received the Bangla Academy 
Award for his contribution to Bengali Literature in 1981.

\section{References}

Ayer, Pico (1993). The Empire Writes Back. Time.

Bassnett, Susan and Trivedi, Harish (ed.) (1999). Post-colonial Translation: Theory and Practice. London and NY: Routledge.

Bhabha, Homi (1994). The Location of Culture. London and New York: Routledge.

Menon, Ritu (2001). "Publishing and Translation" in Rukmini Bhaya Nair (ed), Translation, Text and Theory: The Paradigm of India. New Delhi: Sage Publications.

Mukherjee, Meenakshi (2000). The Perishable Empire. New Delhi: Oxford University Press.

Mukherjee, Meenakshi (2000). The Vintage Book of Indian Writing 1947-1997. New Delhi: Oxford University Press.

Niranjana, Tejaswini (1992). Siting Translation. Hyderabad: Orient Longman.

Venuti, Lawrence (ed.)(1992). Rethinking Translation: Discourse, Subjectivity, Ideology. London and NY: Routledge. 
Trivedi, Harish "India and Post-colonial Discourse" in Kar.C.Prafulla (ed) Critical Theory: Western and Indian. (1997). New Delhi: Pencraft International.

Tharu, Susie and Lalitha K (ed.) (1991). Women Writing in India. New Delhi: Oxford University Press.

Viswanatha, Vanamala and Simon, Sherry (1999). "Shifting grounds of exchange: B.M. Srikantiah and Kannada translation" in Harish Trivedi and Susan Bassnett (ed) Post-colonial Translation: Theory and Practice. London and NY: Routledge. 